\title{
An Eco-System Approach to Project-Based Learning in Software Engineering Education
}

Daniel Ståhl, Kristian Sandahl and Lena Buffoni

The self-archived postprint version of this journal article is available at Linköping University Institutional Repository (DiVA):

http://urn.kb.se/resolve?urn=urn:nbn:se:liu:diva-182363

N.B.: When citing this work, cite the original publication.

Ståhl, D., Sandahl, K., Buffoni, L., (2022), An Eco-System Approach to Project-Based Learning in Software Engineering Education, IEEE Transactions on Education.

https://doi.org/10.1109/TE.2021.3137344

Original publication available at:

https://doi.org/10.1109/TE.2021.3137344

Copyright: Institute of Electrical and Electronics Engineers

http://www.ieee.org/index.html

(C)2022 IEEE. Personal use of this material is permitted. However, permission to reprint/republish this material for advertising or promotional purposes or for creating new collective works for resale or redistribution to servers or lists, or to reuse any copyrighted component of this work in other works must be obtained from the IEEE. 


\title{
An Eco-System Approach to Project-Based Learning in Software Engineering Education
}

\author{
Daniel Ståhl, Kristian Sandahl, Senior Member, IEEE, Lena Buffoni
}

\begin{abstract}
Contribution: This article identifies the participation of external stakeholders as a key contributing factor for positive outcomes in project-based software engineering courses. A model for overlapping virtuous circles of lasting positive impact on both stakeholders and students from such courses is proposed.

Background: Project-based courses are widespread in software engineering education, and there are numerous designs for such courses presented in literature. It is found that the needs and motivations of external stakeholders, from industry and government sectors, in these courses has received limited attention in related work.

Intended Outcomes: A course design that prepares students for graduate level studies and professional life, through close proximity to external stakeholders in a highly realistic setting, working on "live" projects.

Application Design: Building on a long tradition of universityindustry collaboration dating back to 1977 , as well as findings in related work, students are assigned to "live" projects proposed by external stakeholders from industry and government, working in close proximity with their respective stakeholders throughout the project. The course places great emphasis on coaching over instruction, treating the many unforeseen challenges of such projects as a valuable part of the learning experience.

Findings: Based on interviews with stakeholders and students, it is found that stakeholder and student outcomes are interdependent and build upon one another, and that positive outcomes for both groups are necessary for the sustainability of the course over multiple iterations.
\end{abstract}

Index Terms-Case Study, Project based learning, Undergraduate, Graduate education, Industry involvement

\section{INTRODUCTION}

$\mathbf{P}$ ROJECT-BASED courses have long been a mainstay of computer science and software engineering curricula, and are widely acknowledged for their established benefits to students' educational experience - particularly with regards to "soft" learning objectives, such as communication, planning, self-reliance and teamwork, and their role in preparing students for a professional career [1]-[6]. Project-based courses can take many shapes, however. Variables that affect the student's experience include project group size, emphasis on process versus result, degree of supervision and the provenance and type of project assignments [1]-[3], [7], [8].

This paper presents a study of the lasting impact on both students and external stakeholders (a.k.a. clients or customers) from a project-based software engineering course - part of the mandatory third-year MSc curriculum — at Linköping University, Sweden. As the authors observe significant positive effects of inviting such external stakeholders from private

The authors are with the Department of Computer and Information Science, Linköping University, Linköping, Sweden (e-mail: daniel.stahl@liu.se, kristian.sandahl@liu.se, lena.buffoni@liu.se).

Manuscript received Month xx, 2021; revised Month xx, 2021. industry, government and/or civil society, this paper seeks to highlight and investigate success factors for lasting positive impact for not only the students taking the course, but also for the stakeholders themselves. This is done from the perspective of the relationship between the university, the students and the external stakeholders as a holistic ecosystem, requiring positive outcomes for all participants to be sustainable - an area found to be under-researched in published literature.

The contribution of this paper is two-fold. First, it describes and documents a successful project-based setup, along with an analysis of its lasting impact on both students and stakeholders, as one example of applied project-based teaching methodology. Second, it presents a model of the student-universitystakeholder relationship in such project-based courses as an ecosystem, and presents a set of contributing factors to keeping that ecosystem productive and sustainable.

The remainder of the paper is structured as follows. The motivation for and background of the study is presented in Section II, and the research method is described in Section III. The interviews and interviewees are portrayed along with the quantitative findings in Section IV-A, whereupon a thematic coding analysis of the data is available in Section IV-B. Based on this analysis, the research question is discussed in Section IV-C. Finally, threats to validity and reliability are discussed in Section V, whereupon the paper is concluded in Section VI.

\section{Motivation}

This section describes the background of the course and the reasons for conducting the study, along with an overview of related work.

\section{A. Background}

Linköping University has a long tradition of including project-based courses in the software engineering curriculum. In these projects, significant emphasis is placed on waysof-working aspects and creating a realistic software industry experience. In other words, the learning objectives of "soft" skills and preparing the students for professional life as software engineers are prioritized over specific technical skills. Accordingly, the students' behavior during the project is given greater weight than the end result in evaluation and grading - the journey is the destination. The course is similar to the concept of capstone courses, with the key difference that it is placed in the third year of two five-year curriculae. The curriculae comprise both the first and second learning cycles of the European Bologna process [9]. The first cycle is three years, and at that point there is an opportunity for students 
to apply for a BSc degree and leave the university. However, most students proceed with the second cycle directly, studying another two years to earn an MSc degree in either Computer Science and Engineering or Computer Science and Software Engineering, depending on the proportion of hardware courses. Consequently, the course described in this project serves both as a capstone course for the BSc program - with an individual report authored by the students following the project serving as a bachelor's thesis - and as preparation for graduate level studies in the second Bologna learning cycle.

To emulate a realistic project experience, the students are randomly sorted into groups, where they need to to selforganize by accepting pre-defined roles (Test Lead, Architecture Lead, Quality Lead, Team Lead, Analysis Lead, Development Lead and Documentation and Configuration Management Lead). The default group size is 7 , with an equal number of roles. In groups of 6 (due to drop-outs) or 8 (due to the total number of students not being divisible by 7) members, some roles are merged or split accordingly. The group size has been chosen to be large enough to give rise to non-trivial group dynamics, yet small enough to be representative of a typical software development team in the industry. Furthermore, it is emphasized that the roles signify primary responsibility not division of labor. To exemplify, the Development Lead is not solely responsible for developing the software, just as the Documentation and Configuration Management Lead is not solely responsible for writing all the documentation.

Each project group is paired with an external stakeholder from private industry companies, government or civil society, bringing an actual project assignment driven by real-life needs. To maximize student motivation and the chances of a successful student-stakeholder relationship, each project group submits their top picks from a smorgasbord of stakeholder project proposals, whereupon student groups and project proposals are matched.

This matching process requires a sufficient number of project proposals, but in any given year, there is a significantly larger number of project proposals than student groups. In the authors' experience, this is the result of two equally important factors: a close relationship between the university and the local software industry - placing the course in a larger collaborative context — and a high degree of stakeholder satisfaction, leading them to become "repeat customers".

Apart from a strong focus on process over result, the course also emphasizes learning by doing. While each group is provided a supervisor - either a senior student or a teacher - their purpose is not to provide answers, but to coach the students in finding their own solutions.

Based on experiences from this course, and the emphasis placed on the role of the external stakeholders, the authors wanted to better understand its lasting impact on both students and stakeholders, viewed through the lens of longterm sustainability of the course: to successfully repeat the course year after year requires a steady supply of external stakeholders willing to invest their time and energy. This highlights the important of considering impact not only on the students (a subject well documented in literature, as shown in Section II-B), but also on the stakeholders.

\section{B. Related Work}

There is a substantial body of knowledge identifying the benefits to students in computer science and software engineering of having at least some project-based elements in the curriculum: elements where students come together to collaboratively solve a common problem through requirements management, system design, development, testing and ultimately delivery of the software system. Indeed, project-based courses as a recommendation can be traced back to the late '60s [2], and such courses have been part of the software engineering curriculum of the authors' own university since 1977. Today, the benefits of project-based courses are widely accepted and recommended in international guidelines [10], [11], based on their recognized ability to integrate skills and insights gained in earlier courses, while at the same time preparing students for professional life as software engineers.

1) The Student's Point of View: From an international perspective, BSc level project-based software engineering courses are generally found in the final year of the curriculum. Such courses are often known as capstone courses, and the student's perspective in these courses is well documented in published literature. There are numerous experience reports of the learning objectives - implicit or explicit - achieved by the students. Most common among such these are "soft" skills:

- Teamwork [1], [2], [4], [12], [13]

- Problem solving and critical thinking [3], [4], [14]

- Team internal and external communication [2], [3]

- Self-directed learning [1], [7]

- Project management [1], [3], [13]

Furthermore, there are reports of positive impact from project-based courses on students' attitude towards the software engineering discipline [14] and supporting students in making career decisions [1], [4], [5]. In stark contrast to "soft" skills, reports on technical skills from project-based courses are comparably rare. When such learning objectives are mentioned they tend to be put in general terms, e.g. independently of programming languages used [4]. One example of this is how [2] reports on the introduction of continuous integration and delivery tools and practices, which the students experience direct benefits from in their subsequent project.

Project courses also present an opportunity to introduce auxiliary learning objectives, not directly connected to the completion of the project assignment. Successful examples reported in literature include:

- Entrepreneurship [12]

- SCRUM [6]

- Global Software Engineering (GSE) [5]

- Free open source software and altruism [14]

- Reflection-based experience building [15]

A recently published literature review also shows that project-based courses are often used to introduce current industry trends into the curriculum, among which Agile development is the most common: out of 126 reviewed papers, 104 mention the use of project-based learning in this context [8].

It is not uncommon for project-based software engineering courses to invite actual, external "clients" or "customers" (in 
this study, the term "stakeholders" is used) with real-life needs from private industry, government and/or civil society. This has been found to increase the motivation of students [6], [12] and provide a more realistic experience of practical elements of a software engineering project [8]. Other motivational factors include varied ways of working compared to non-project-based courses [12] and that a completed project-based course can serve as a qualification for future employment [1], [5], [13].

2) The Stakeholder's Point of View: Given the potential of added value from inviting external stakeholders to participate in project-based learning, it is important to understand the stakeholder's perspective: their reasons for participating, as well as experienced opportunities and challenges. Even so, the stakeholder's perspective is not as well documented as that of the student. Two exceptions to this are Paasivaara et al. [6] and Höst et al. [16], who describe a project-based course with external stakeholder involvement, and experiences from MSc thesis projects, respectively. Both of these identify the opportunity for recruitment and maintaining a strong industry-university relationship, more generally, as key driving factors for stakeholder involvement. Another benefit for the stakeholders is the opportunity to try out new ideas and explore untried concepts, and that bringing in students to consider a problem with fresh eyes is valuable in itself, and that outcomes of such exploratory projects may then be operationalized and potentially monetized - by the stakeholders further on.

In the project-based course described by Paasivaara et al. [6], the stakeholders act as SCRUM product owners, which implies a high degree of participation. An interesting finding in these projects is that stakeholders aren't necessarily interested in the actual software developed by the students. Rather, for some stakeholders, the software appears to be a by-product of lesser importance than other values, such as insights gained and connections made.

Inviting external participants in project-based courses is not without risks, however, and a model for assessing these risks has been proposed in literature by Steghöfer et al. [17], while noting that such involvement "is desirable due to its potential positive effects on the students". In this work, Steghöfer et al. — working as a "guild of teachers" — reflect on a total of 52 risks, with the two most salient being that the stakeholder may be unable to set aside the promised time, and that teachers and stakeholders use conflicting terminology, respectively.

That being said, it is worth noting that challenges within the student project do not necessarily impact the stakeholder's experience negatively: while difficulties in managing stakeholder expectations and/or managing which tasks to do next and how correlate negatively with stakeholder satisfaction, difficulties in e.g. effort estimation and testing, or having insufficient technical skills do not [18].

\section{RESEARCH METHOD}

Based on the reasoning in Section II, the following research question was phrased: What are the enabling factors of sustainable and lasting impact from external stakeholder participation in project based software engineering learning? To answer this question, a step-wise mixed-method research method was designed.

\section{A. Overview}

A high level overview of this research method is provided in Figure 1:

- Students and stakeholders having participated in the course one year previously were interviewed. The interviews and the interviewees are presented in Section IV-A.

- Thematic coding analysis of the student interviews and stakeholder interviews, respectively, was carried out by each of the researchers individually. The separate analyses were then compared and merged: first by one author, then reviewed and discussed by all of the researchers together. The thematic coding analysis of the interviews is presented in Section IV-B.

- The resulting thematic coding maps (for student and stakeholder interviews, respectively) were then used to discuss and phrase a response to the research question, as presented in Section IV-C.

The methodology of each respective step is described in detail below.

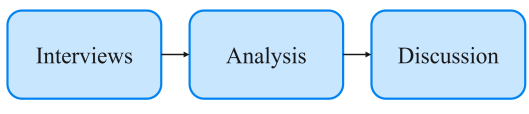

Fig. 1. Research process overview.

\section{B. Interviews}

To assess the lasting impact and enabling factors of the project-based course, interviews were carried out with both students and stakeholders who had participated. To eliminate contextual factors that may affect the results - such as changes in course staff, or the sudden shift to working remotely due to the Covid-19 pandemic — participants from a single year (2019) were selected.

While all of the stakeholders were interviewed, the students were selected according to a semi-random, semi-purposive process. First, interviewee candidates were randomly selected from each of the project groups, with project roles not already represented by other interviewees being given priority (see Section II-A for a description of the course organization). The goal of this selection process was to achieve representation of each role and each project group. The intent of this coverage was to enable the capture of salient concepts which may not be evident for each role or project, rather than to reliably capture every feature of each role, group or combination thereof - something that would require a substantially larger set of interviews. Where interviewee candidates declined to participate the selection process was repeated to produce replacement candidates from the same group.

The interviews were carried out individually and remotely (due to the Covid-19 pandemic), either in English or Swedish, according to each interviewee's preference. Each interview was conducted by one researcher, with each of the researchers interviewing both stakeholders and students, where notes were taken during the interview and shared with the interviewee to ensure correctness. The interviews were semi-structured, following a prepared interview guide for stakeholder and student 
interviews, respectively. The questions in the interview guides were designed to be behavior/experience oriented, according to the guidelines proposed by [19], and complemented by Likert scale [20] questions to assess the self-perceived impact of the course on the interviewees.

In the studied year, the course comprised a total of 11 projects sponsored by 10 individual stakeholders (with one of the stakeholders sponsoring two projects). In total, 28 interviews were carried out: 10 stakeholders and 18 students. The stakeholders represent both private industry (3 stakeholders) and government sectors (7 stakeholders), of which education and public health services formed the majority.

Each of the 11 project groups was represented by at least one interviewee. While the distribution of interviewees across roles was not perfectly equal - a consequence of the random selection process in combination with certain students declining to participate - each role was represented by at least one interviewee.

The interview results are presented in Section IV-A.

\section{Analysis}

The interview results were analyzed in the following steps, according to the thematic coding and analysis guidelines presented by Robson [21]:

- Familiarizing with the data: The transcripts were read and re-read, with initial ideas noted down.

- Generating initial codes: Particular statements of interest across the entire data set were identified and systematically coded.

- Identifying themes: The codes were grouped into candidate themes, which were then checked against codes and other themes to ensure accuracy and avoid overlap. During this process the themes and codes were iteratively revised and refined.

- Integration and interpretation: The data was structured in a thematic map to support subsequent analysis, and the quality of the map was re-evaluated.

For increased reliability, this analysis was first conducted individually by each of the three researchers. The resulting three separate thematic coding maps were then compared in an internal workshop, with differences identified and analyzed. The maps were subsequently merged into a single, shared map agreed upon by all three researchers.

To merge the three thematic coding maps, identical or nearidentical themes were first identified and carried over to the shared map. Where labeling and categorization differed, all three researchers jointly discussed and agreed upon the best option to be carried over to the shared map, whereupon any codes left without a matching theme in the resulting map were analyzed one by one and re-labeled.

The result of this process is presented in Section IV-B.

\section{Discussion}

The themes derived from the thematic coding of student and stakeholder statements, respectively, were then used to derive a response to the research question. Based on the perception that students, course design and stakeholders do not co-exist in perfect isolation, but that any lasting impact from external stakeholder participation sought by the research question might be found in the interplay between these, the themes resulting from the thematic coding analysis were not only studied individually. Instead, relationships in the structure and codes indicating connections between themes were actively sought. Through this process of identification of relationships, with iterative joint discussions between the three researchers, a pattern of circular dependencies emerged, as presented in Section IV-C.

\section{FINDINGS}

\section{A. Interviews}

Two of the most salient topics in related work are the extent to which they prepare for subsequent advanced studies and the impact of project-based courses on students' motivation to pursue careers in software engineering (see Section II-B). Accordingly, Likert scale assessments were included in the interview guide to let the students reflect on these questions. The responses are presented as Preparation and Motivation, respectively, in Figure 2. As shown in the figure, their responses were positive - confirming the experiences reported in related work - but not overwhelming. With regards to Preparation in particular, nearly all students responded with Slightly better (i.e. 4 out of 5). The qualitative comments made by several of the interviewees shed some light on this. While the course was helpful in training them to e.g. "read and write reports", it was generally felt that advanced level studies were not all that different from undergraduate studies: "I don't think it prepared me for advanced studies, but that it prepared me for a professional career" and "I would like to change advanced level courses more than I would like to change this one". Indeed, one interviewee declined to respond, saying that the project-based course was more the culmination of their studies than it was preparatory - in line with the concept of a capstone course.

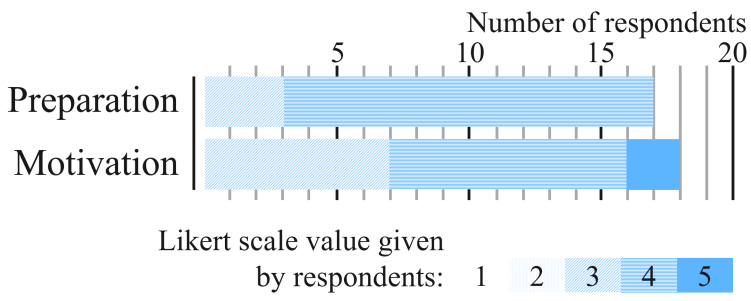

Fig. 2. Likert scale responses for Preparation and Motivation.

While many students experienced an increased interest in a professional software engineering career as a result of the course, a large minority did not. It is worth noting that most of these (4 out of 7) emphasized that this did not reflect disinterest, but rather an already strong interest being confirmed: in the words of one interviewee, "it wasn't a revelation [but] more of a confirmation".

In contrast, as shown in Figure 3, the stakeholders gave overwhelmingly positive responses when asked, on a scale from 1 ("Never") to 5 ("Certain"), how likely they were to 
recommend other potential stakeholders to participate in the course (Recommendation, in the figure). This is particularly interesting when compared to the more balanced - although still positive - view of the project outcomes (Value in Figure 3). This difference might seem paradoxical, but should be viewed in light of the reports from related work that the delivered software may not be the stakeholders' main objective (see Section II-B2).

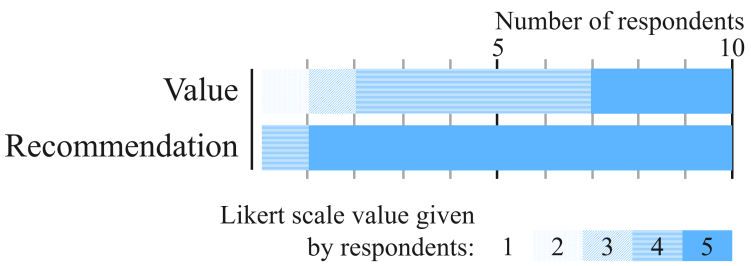

Fig. 3. Likert scale responses for Value and Recommendation.

\section{B. Thematic Coding Analysis}

Two thematic coding maps were created from the interview data - one for the students and one for the stakeholders according to the process described in Section III-C.

1) Student Interview Data: The thematic coding map for the student interviews comprises five top-level themes (see Figure 4), presented in turn below.

- Course Impressions: The largest number statements in this theme, by far, relate to the interaction with the stakeholders and the realism of the project - the vast majority of these underlining how important these are to the students' positive perception of the course. Interviewees remark how it was "fun to work with a real company", that "it was interesting to have a [real] customer and realize that the assignment changes as the project progresses" and that is was instructive "because it was an external project". Several students remarked that the project was very similar to previous work-life experiences (e.g. summer internships) and that "you felt the work was for real" and that "you created something real", not only motivating them to complete the project, but giving them a sense of having chosen the right education. This sense of realism lends support to including common industry practices in project-based courses, as reported in related work (see Section II-B).

The second largest sub-theme is related to roles within the project group. In some groups the roles mattered less, because they would share the workload, while in other groups the students' roles had significant impact on their experience. Even so, the vast majority of the interviewees had a positive view on their role: either because it was a role they wanted and that fit them well or because it helped them learn of a new aspect of software engineering they weren't previously familiar with (typically something other than actual programming, e.g. "I chose the [configuration management] role because I wanted to learn more about Git"). One interviewee felt that their role (as Test Lead) had a negative impact on their experience, because the rest of the group didn't see it as relevant.

A number of statements related to the role of the supervisors. An explicit part of the didactic underpinnings of the course is to coach the students rather than instruct them: strengthening the students' ability to see the project through to the end by making all the unforeseen complications that naturally arise in a real world setting part of the course and encouraging then to find their own ways to overcome them, rather than to pave the way for them. This approach also finds support in the interviews, e.g. commenting that the supervisors "are demanding, but that is positive" and "I can't think of a single instance where we ourselves didn't solve the problems we encountered". In turn, this opportunity for the students to explore their own abilities is a large part of their take-away experience: "you become self-reliant; you don't need the step-by-step instructions you receive [in other courses]". At the same time, it is an approach that requires a sufficient level of student motivation to be successful. It is worth noting that this approach is the result of a continual joint learning between teachers and supervisors, where the supervisors' experiences of what works and what doesn't are fed into the following iteration of the course to continually improve the student experience.

Finally, the students are generally highly motivated even as the course begins. This is partly explained by it being a high-profile course in the curriculum, and partly by word-of-mouth: positive experiences shared with junior students adds to the sense of the course as what their studies "have led up to".

- Acquired Skills and Experiences: The acquired skills and experiences reported by the interviewees are for the most part not technical, in line with the findings in related work (see Section II-B1). The acquired technical skills that are valued by the students afterwards are "meta-skills", such as software configuration management, continuous practices or testing, which are generally applicable.

In contrast, the interviewees speak at length about their acquired "soft" skills, pertaining to planning and organizing, responsibility and self-reliance and communication, respectively. One interviewee notes that being placed in a randomized group makes all the difference, because "in other project courses you often work with your friends", while being placed in a relatively large group of random people forces one to practice one's social skills and recognize the importance of coordinating with others. In the words of the interviewees, "I realized [how] difficult it is to coordinate people" and "it has become clear to me that professional life will be at least as much social interaction as pure implementation [and that] it can't be ignored".

- Relation to Other Studies: As noted in Section IV-A, a common observation was that the course did not prepare for subsequent studies so much as for a professional career. Several remarked on the benefits of learning by doing, e.g. saying that "I think it works fairly well to 


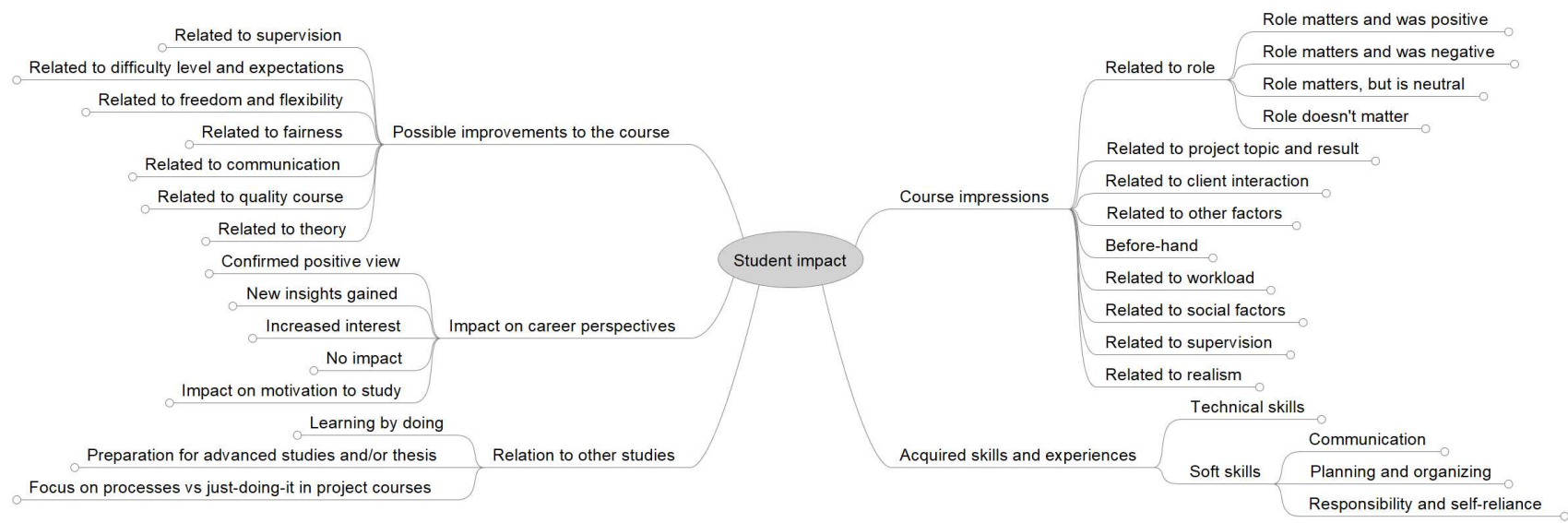

Fig. 4. Themes of the student interview data (individual codes excluded).

be dropped in at the deep end" and that "[the project course] is different from everything else". This last point is particularly relevant, as it reflects statements made spontaneously by five of the interviewed students: that graduate level studies are not as different from the undergraduate curriculum as one might expect, but rather more of the same.

- Impact on Career Perspectives: The thematic analysis confirms the view presented in Section IV-A: most students felt that the course either confirmed an already positive view of a career in software engineering, or strengthened their interest. The majority of the new insights reported by the interviewees was the need for planning, administration and documentation in professional software development. A small minority felt that the assignment they received in the project "wasn't any fun", but that their interest in software engineering generally had not lessened as a consequence.

- Possible Improvements to the course: Many of the suggestions for improvements relate to the randomness of stakeholder relationships. Whereas some groups had stakeholders who were very accessible and spent considerable time bouncing ideas with the team, others felt that they were a low priority for their stakeholders, who would be difficult to get into contact with. This clearly affected the impact of the course on the students - as expected based on the emphasis the students place on stakeholder interaction and realism as positive aspects of the course. Even though many commented on the benefits of the course's focus on process, roles and documentation, some stated that they would have wished for project assignments that were more technically challenging. This balance between process and technology is a difficult to strike, but one that is important to consider when organizing a project-based course involving external stakeholders.

2) Stakeholder Interview Data: The thematic coding map for the stakeholder interviews comprises four top-level themes (see Figure 5), presented in turn below.

- Expectations: For a positive collaboration with external stakeholders, it is important to understand their expectations when committing to participation in the course. Interestingly, none of the stakeholders expected an actual product. Instead, several of them see the students' deliveries as prototypes, e.g. "a demonstration, not a finished product, which can be in a research prototype". One stakeholder, who had participated previously, remarked that "the first time [we] expected an actual product" but now were of the opinion that "the final product isn't necessarily the goal; we want to understand if our vision is correct". This view of students as effective in "testing early ideas" was shared by multiple stakeholders, as was the expectation to find talent and identify future recruitment opportunities. This is a finding that may run contrary to intuition, even while it connects to the larger theme of the course, that the journey is the destination (see Section II-A).

- Outcomes: While some projects have resulted in live products (e.g. a surgery planning tool used by the public health service), the majority of the projects resulted in prototypes - in other words, the stakeholders largely got what they expected from the projects. What, if anything, these prototypes ultimately result in is largely dependent on the stakeholders themselves, though, with stakeholders' internal readiness and willingness to develop them further being varied.

Emphasizing that the end product is less important than the experience gained (in line with reports from related work, see Section II-B2), one stakeholder notes that the product was "a failure", but valuable even so in that it successfully demonstrated a need for a product while establishing how not to implement it. This serves as an example of how the outcome of the student project is likely different, but still valuable, compared to what an in-house or commercially sourced project would have delivered. Indeed, some stakeholders who have participated previously remark that they have gradually shifted their expectations over time from the delivery itself to focus more on the exploration and learning benefits.

To summarize, most stakeholders view the student 


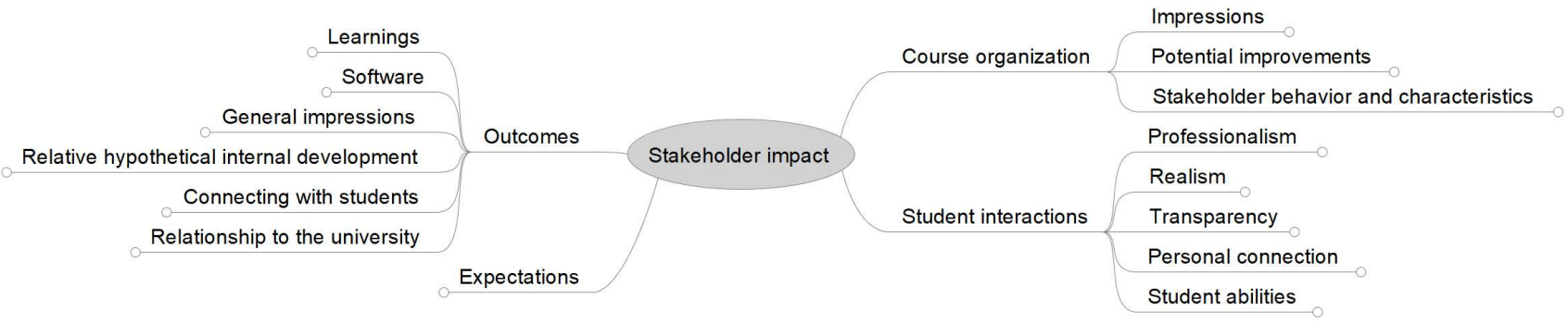

Fig. 5. Themes of the stakeholder interview data (individual codes excluded).

projects not as an alternative method of product development, but as a low cost, low risk and rapid method of exploring opportunities they otherwise could not (or would not) have invested resources in, while at the same connecting with young engineers to potentially recruit further on.

- Student Interactions: A potential fear when considering external participation in project courses is that students might behave irresponsibly, or otherwise cause incidents that could reflect poorly on the university. The stakeholder interviewees indicate that such fears are unfounded: there is a broad consensus that the students' behavior is "professional", "impressive" and "dependable" and that they would persevere through unexpected challenges, of which there can be quite a few (indeed, stakeholders view a major part of the value to be the encountering and uncovering of such challenges). Most stakeholders did not find that the students demanded too much attention, though. On the contrary, several remarked that they would like to see "a close connection" and "spontaneous meetings where we can have a discussion and I can motivate them".

- Course Organization: The general impression from the stakeholders is that "the course is well organized". The possible improvements suggested can be sorted into two broad categories. First, closer student interaction, particularly with the entire group (e.g. "to meet the entire group, giving a greater opportunity to understand details in the project and get to know the individuals"). Second, even greater focus on iterative methodology, emphasizing the importance of early value creation (e.g. "push the students to make something very simple and demo early") that can be adapted depending on the nature of the project.

Several stakeholders also reflected on how their own behaviors contribute to a successful project. They highlighted the importance of staying involved and setting aside the time to be available, meeting regularly with the students and answering questions (e.g. "you have to take the time to be engaged as a customer"). The importance of preparing internally to capitalize on the outcome of the student project was also identified (e.g. "it would have been better if [we] had a co-developer in our department who could have taken over [after the project course ended]").

\section{Discussion}

This section discusses the findings presented in Section IV-B through the lens of the research question: What are the enabling factors of sustainable and lasting impact from external stakeholder participation in project based software engineering learning?

1) Modeling the Eco-System: The interview data strongly supports a positive impact on both classes of participants. This is not least evident in the Likert responses (see Section IV-A) and is completely in line with the findings in related work (see Section II-B). Moreover, while some "capstone courses" do not involve external participants (see Section II-B) and the role of and impact on external stakeholders is not emphasized in most related work, the interview data shows that these external stakeholders play a critical role in shaping the positive impact on the students, strengthening the need to identify the enabling factors for sustaining stakeholder involvement year over year. Through analysis of the thematic coding maps, as described in Section III-D, it was found that the interview data points to the existence of overlapping and mutually reinforcing feedback loops for the impact on the participation and the vigor of this ecosystem (see Figure 6).

The lasting impact on students (item $\mathbf{A}$ in Figure 6) is shaped by their experience from the course (B). This is partly dependent on how teachers and supervisors frame the challenges and guide the students - something that continually evolves through not only student feedback, a close joint learning dialog between supervisors and teachers with the supervisors (C) - but also the students' ability to persevere in the face of challenges (D), as evident from the interview data. Also shown in the interviews is the importance both of the students' own motivation (E) to complete the course and the supervisors' tendency to coach rather than instruct the students, and treat any unexpected challenges as part of the course rather than obstacles to be removed $(\mathbf{F})$. This motivation is supported by the course having a prominent position in the curriculum and being actively promoted already in the first year as an important and rewarding course $(\mathbf{G})$, but perhaps more importantly by the student experiences of previous years, spreading by word of mouth (B). In this way, it can be argued that the impact on students is the result of an intricate chain of factors that is gradually built up over several iterations.

The course and its students do not exist in isolation, however. What is clear from the interviews is that the students' perseverance (D) is highly influenced by the stakeholder's participation (L); several interviews highlighted this as a 


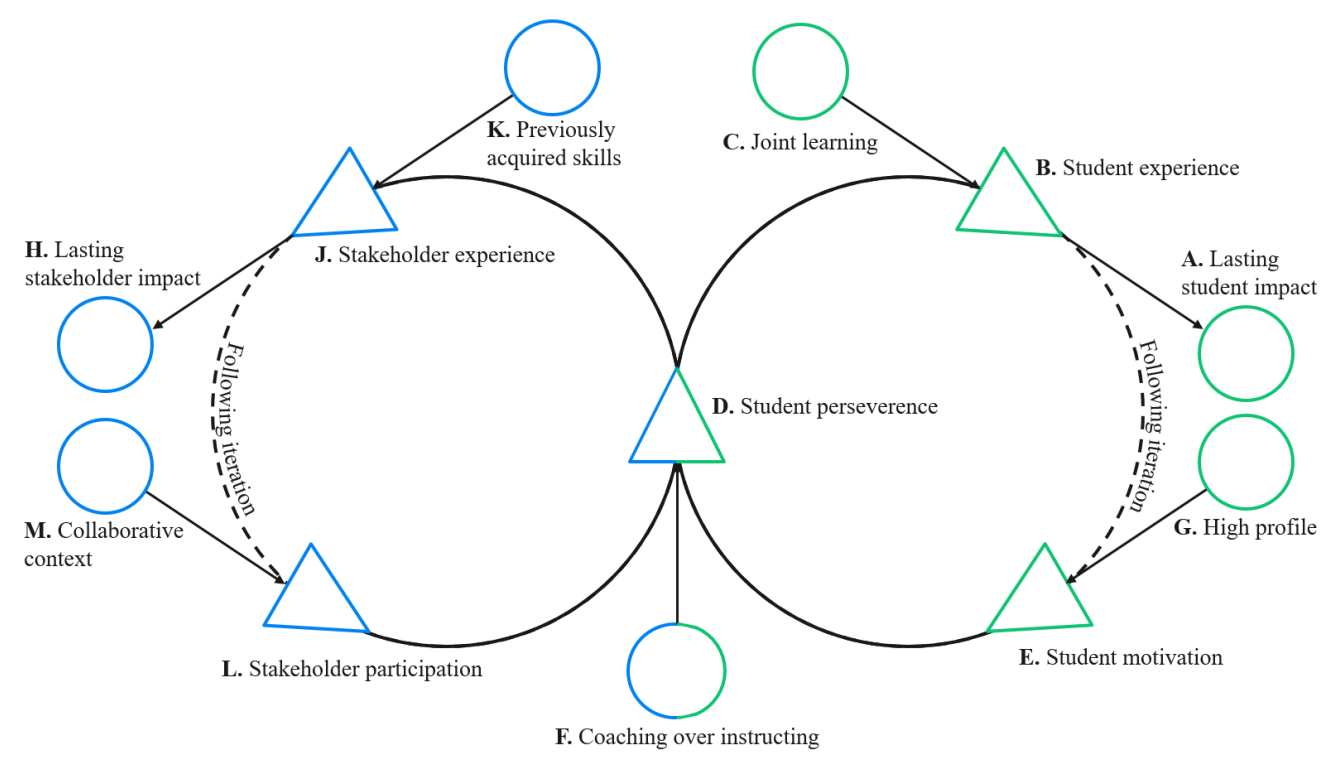

Fig. 6. Reinforcing loops in the student-stakeholder-university ecosystem.

crucial factor, with the presence of an actual customer helping them pull through encountered difficulties. The stakeholder interviews clearly showed that for many of them, participating in the project course builds on an existing confidence and is only one part of a larger tradition of collaboration between the university and local industry $(\mathbf{M})$. It is worth noting that one aspect of this is that several of the participating companies are also represented in university committees and boards at multiple levels, reflecting an institutionalized collaboration. Another important factor in the stakeholders' participation were their experiences from past iterations of the course: with positive outcomes from previous years, they were eager to repeat the experience and explained how they strove to become "better customers" (J). Producing those positive outcomes depends in turn on both the students' perseverance and willingness to overcome the challenges they encounter along the way (D) and possessing the required skills (K), with a relevant preceding curriculum being the university's means of bestowing those skills. As one stakeholder put it, they were "impressed by what the students have already learned". And ultimately, just as the lasting impact on students is shaped by their experiences from the course, the lasting impact on the stakeholders $(\mathbf{H})$ ultimately depends on their experience $(\mathbf{J})$ - whether that is an experience of a delivered product, the thought-provoking exploration of an idea or "a successful failure".

2) Applying the Model: The proposed model offers multiple opportunities to support educators in setting up a conducive context in which to conduct their project-based learning courses with external stakeholders. Below the authors' reflections on the ways in which the model shown in Figure 6 can support course design and execution are offered.

- The long view: Perhaps the most significant aspect of the proposed model is its reinforcing loops, and the fact that these span multiple iterations of the course. The implication of this for educators is to take the long view: setting up a project-based course involving external stakeholders requires perseverance. A less-than-perfect result the first iteration should not be seen as failure or invalidation of the notion. Rather, emphasis should be placed on providing both students and stakeholders with positive experiences following the course, thereby enabling improvements iteration by iteration.

- Managing expectations: An important part in securing those positive experiences is to manage the stakeholders' expectations beforehand. The interview data clearly shows that stakeholders often do not get a working product at the end of the project, but that they are very satisfied even so. It is also clear that the more experienced stakeholders, who have participated previous iterations, knew to expect this and were prepared for it. Indeed, it can be observed how over time they come to regard the course not as a way of getting software delivered, but as a way of exploring opportunities with a fresh perspective and trying out concepts they would not have had time or budget for otherwise. Therefore, proactively managing these expectations, so that firsttime stakeholders also know what to expect, is a crucial element in enabling a positive experience: not only for the stakeholders themselves, but also for the students by avoiding a sense of failure in case they cannot deliver a deployment ready solution.

- Inward anchoring: An important factor in the outcome of projects is the perseverance of the students in face of adversity - and some degree of adversity in such projects is always to be expected. As shown in the proposed model, one factor influencing the students' perseverance is their motivation to complete the course in the first place, which in turn is impacted both by the experiences of senior students and by how actively the course is promoted in the curriculum. The former is related to taking The long view, as discussed above, whereas the latter is largely a function of the emphasis the university 
puts on the course in communications. It should be noted that such emphasis can be difficult to effect, however, as it tends to come at the expense of other courses in the curriculum.

- Outward anchoring: Attracting prospective stakeholders to a project-based course can be hard and timeconsuming work, particularly for individual educators. Nevertheless, as shown in the proposed model, it's an important factor in creating a sustainable eco-system supporting the course. Consequently, the case can be made that such courses benefit from being an integral part of any larger industry collaboration program the university might engage in, providing networking opportunities and a collaborative framing in which industry representatives are easier to identify and approach for participation in the course.

- Matching projects to curriculae: One of the contributing factors to a positive stakeholder experience is perhaps unsurprisingly — the skills previously acquired by the students as part of their studies. In practice, not even the best curriculum can cover every potential technology that might be needed in an industry project, but where there is room for adjusting stakeholders' project proposals to better match the student curriculum there is a greater chance of a successful outcome. Naturally, this is easier with a larger pool of project proposals to choose from (reinforcing the importance of The long view, as outlined above), but even where one does not have the luxury of picking and choosing it may be possible to nudge projects in a direction that is more closely aligned to the curriculum. It is worth pointing out that this is a two way street, however: the types of technologies external stakeholders require in a project-based course can be used by the university as a signal as to which technologies to include in the curriculum to keep it relevant.

- Facilitation of stakeholder-student interaction: Evident from the interviews, and represented in the model, is the importance of active and positive stakeholder involvement with the students for their motivation and perseverance - and ultimately for both stakeholder and student experiences from the project. Both frequency and inclusivity of these interactions are important factors to consider, implying the value of formats where the entire group (as opposed to one or two representatives) engage with the customer. In addition, similar to Managing expectations, preparing the stakeholders for this by explaining the importance of student interaction to them is key in forestalling misunderstandings caused by absent or inactive customers once the project is under way.

\section{THREATS TO VALIDITY AND RELIABILITY}

This section discusses threats to construct validity, internal validity and external validity.

\section{A. Threats to Construct Validity}

A threat to construct validity is the fact that the interviews occurred in the interval of 12-18 months after the course. To understand even longer lasting impact, a more longitudinal study would be required. The authors regard this a promising area of further work, but note that a carefully designed methodology would be required to guard against potential threats to validity from the fact that separate cohorts may have different perspectives on the course, both as a consequence of changing circumstances in the course and of maturation.

\section{B. Threats to Internal Validity}

A number of the interviewed stakeholders have a close relationship to one or more of the researchers, something that may pose a validity threat. To a certain extent, the existence of such close relationships is inevitable given the collaborative context of the course (discussed in Section IV-C). This threat is further mitigated by randomly distributing the stakeholder interviews between the researchers, and similarly positive responses can be found regardless of interviewer. In a similar vein, though all of the interviewed students had passed the course at the time of the interviews, it is conceivable that they would feel pressure to respond in a certain way as the interviewers also teach other courses where the students may find themselves in a position of dependency. However, only one of the student interviewees was enrolled in courses given by their interviewer, and there are no signs in the interview data that their responses were significantly different.

Another threat to the internal validity of the study is the sample size of 18 student interviews. This constitutes a minority of the course participants, but in thematic coding analysis a key objective is to achieve saturation. As noted by [22], determining when saturation has been achieved can be challenging. In this work, the aim has been to reach the point where additional data "fails to add properties or dimensions" [23]. In this study, such saturation occurred at approximately 13 interviews, with some slight variation between the separate parallel analysis efforts (see Section III-C). This is in line with findings in related work, where the number of new concepts generated in analysis tends to drop sharply after the first 10-15 interviews [24].

Finally, even though the student interviewee selection was randomized (see Section III-B), participation was voluntary and not all selected interviewees chose to respond. Therefore it is conceivable that particularly engaged (and perhaps positive) students were inadvertently selected for in this process. On the other hand, the interview data corresponds well with the feedback collected for all courses given at the faculty.

\section{Threats to External Validity}

There are several variables unique to the studied case such as the university context, and the specific companies and individuals involved - which pose a threat to generalizability. That being said, the external validity hinges on the ability to transfer the results to other settings with similar properties. In that spirit, this research has been positioned in relation to related work, and taken care to described the context and design of the studied course. Consequently, it can be argued that teachers in other project-based courses should be able to compare their context to ours and decide which findings are applicable, and which may not be. 


\section{Threats to Reliability}

To guard against erroneous conclusions caused by incorrect application of the study methodology, the thematic analysis of the interview data was conducted separately by each of the researchers, as described in Section III-C. The results were then compared, any discrepancies discussed and the thematic maps ultimately merged. To ensure the correctness of the interview data itself, all transcripts were read back verbatim to the interviewees.

\section{CONCLUSION}

In this impact case study the impact has been analyzed one year after course completion - for both students and stakeholders of a project based software engineering course with strong elements of external stakeholder collaboration, giving students the opportunity to work on projects proposed by local industry, government and/or civil society. This collaboration is identified as a strongly contributing factor to the positive impact of the course, and present a model of overlapping feedback loops that enable the collaboration to be sustained over multiple iterations of the course.

This is significant in that similar project based courses (sometimes referred to as "capstone" courses) are a very common element in university level software engineering curricula. Therefore, the identification of success factors for providing lasting and sustainable positive impact in such courses is critical for the education of new generations of software engineering professionals.

Salient avenues of further work are found to include a more longitudinal study of longer lasting impact (see Section V-A) as well as the systematic comparison of the effects of different forms of industry collaboration in project based software engineering courses. It is also recognized that application of the proposed model of the eco-system would benefit from empirical validation, which the authors regard as a valuable area of further work.

\section{ACKNOWLEDGMENT}

The authors would like to thank all of the students and project stakeholders who generously shared their time and insights.

\section{REFERENCES}

[1] M. Spichkova, "Industry-oriented project-based learning of software engineering," in 2019 24th International Conference on Engineering of Complex Computer Systems (ICECCS). IEEE, 2019, pp. 51-60.

[2] B. Bruegge, S. Krusche, and L. Alperowitz, "Software engineering project courses with industrial clients," ACM Transactions on Computing Education (TOCE), vol. 15, no. 4, pp. 1-31, 2015.

[3] J. Khakurel and J. Porras, "The effect of real-world capstone project in an acquisition of soft skills among software engineering students," in 2020 IEEE 32nd Conference on Software Engineering Education and Training (CSEE\&T). IEEE, 2020, pp. 1-9.

[4] M. Exter, S. Caskurlu, and T. Fernandez, "Comparing computing professionals' perceptions of importance of skills and knowledge on the job and coverage in undergraduate experiences," ACM Transactions on Computing Education (TOCE), vol. 18, no. 4, pp. 1-29, 2018.

[5] I. Bosnić, I. Čavrak, and M. Žagar, "Assessing the impact of the distributed software development course on the careers of young software engineers," ACM Transactions on Computing Education (TOCE), vol. 19 , no. 2 , pp. 1-27, 2019 .
[6] M. Paasivaara, J. Vanhanen, and C. Lassenius, "Collaborating with industrial customers in a capstone project course: the customers' perspective," in 2019 IEEE/ACM 41 st International Conference on Software Engineering: Software Engineering Education and Training (ICSESEET). IEEE, 2019, pp. 12-22.

[7] J. Larson, S. S. Jordan, M. Lande, and S. Weiner, "Supporting selfdirected learning in a project-based embedded systems design course," IEEE Transactions on Education, vol. 63, no. 2, pp. 88-97, 2020.

[8] O. Cico, L. Jaccheri, A. Nguyen-Duc, and H. Zhang, "Exploring the intersection between software industry and software engineering education-a systematic mapping of software engineering trends," Journal of Systems and Software, vol. 172, p. 110736, 2021

[9] The European Commission, "The Bologna Process and the European Higher Education Area," https://ec.europa.eu/education/policies/highereducation/bologna-process-and-european-higher-education-area, 2020 , [Online; accessed 22-September-2021].

[10] R. Adcock, E. Alef, B. Amato, M. Ardis, L. Bernstein, B. Boehm, P. Bourque, J. Brackett, M. Cantor, L. Cassel, R. Edson, R. Fairley, D. Frailey, G. Hafen, T. Hilburn, G. Hislop, D. Klappholz, P. Kruchten, P. Laplante, Q. L. Li, S. Lucero, J. McDermid, J. McDonald, E. McDuffie, B. Michael, W. Milam, K. Nidiffer, A. Pyster, P. Robitaille, M. Shaw, S. Sheard, R. Suritis, M. Towhidnejad, R. Thayer, J. B. Thompson, G. Travassos, R. Turner, J. Urban, R. Valerdi, O. Vikman, D. Weiss, and M. J. Willshire, "Curriculum guidelines for graduate degree programs in software engineering," New York, NY, USA, Tech. Rep., 2009.

[11] M. Ardis, D. Budgen, G. Hislop, J. Offutt, M. Sebern, and W. Visser, "Se 2014: Curriculum guidelines for undergraduate degree programs in software engineering," Computer, vol. 48, no. 11, pp. 106-109, 2015, cited By 30.

[12] H. Burden, J.-P. Steghöfer, and O. H. Svensson, "Facilitating entrepreneurial experiences through a software engineering project course," in 2019 IEEE/ACM 41st International Conference on Software Engineering: Software Engineering Education and Training (ICSE-SEET). IEEE, 2019, pp. 28-37.

[13] H. M. Haddad, "One-semester cs capstone: A 40-60 teaching approach," in 2013 10th International Conference on Information Technology: New Generations. IEEE, 2013, pp. 97-102.

[14] H. J. Ellis, G. W. Hislop, S. Jackson, and L. Postner, "Team project experiences in humanitarian free and open source software (hfoss)," ACM Transactions on Computing Education (TOCE), vol. 15, no. 4, pp. 1-23, 2015.

[15] M. Marques, S. F. Ochoa, M. C. Bastarrica, and F. J. Gutierrez, "Enhancing the student learning experience in software engineering project courses," IEEE Transactions on Education, vol. 61, no. 1, pp. 63-73, 2017.

[16] M. Höst, R. Feldt, and F. Lüders, "Support for different roles in software engineering master's thesis projects," IEEE Transactions on Education, vol. 53, no. 2, pp. 288-296, 2009.

[17] J.-P. Steghöfer, H. Burden, R. Hebig, G. Calikli, R. Feldt, I. Hammouda, J. Horkoff, E. Knauss, and G. Liebel, "Involving external stakeholders in project courses," ACM Transactions on Computing Education (TOCE), vol. 18, no. 2, pp. 1-32, 2018.

[18] J. Vanhanen, T. O. Lehtinen, and C. Lassenius, "Software engineering problems and their relationship to perceived learning and customer satisfaction on a software capstone project," Journal of Systems and Software, vol. 137, pp. 50-66, 2018.

[19] S. E. Hove and B. Anda, "Experiences from conducting semi-structured interviews in empirical software engineering research," in 11th IEEE International Software Metrics Symposium (METRICS'05). IEEE, 2005, pp. 10-pp.

[20] A. Joshi, S. Kale, S. Chandel, and D. K. Pal, "Likert scale: Explored and explained," Current Journal of Applied Science and Technology, pp. 396-403, 2015.

[21] C. Robson and K. McCartan, Real world research. John Wiley \& Sons, 2016.

[22] G. Guest, E. Namey, and M. Chen, "A simple method to assess and report thematic saturation in qualitative research," PLoS One, vol. 15, no. 5, p. e0232076, 2020.

[23] M. Birks and J. Mills, Grounded theory: A practical guide. Sage, 2015.

[24] M. G. Morgan, B. Fischhoff, A. Bostrom, C. J. Atman et al., Risk communication: A mental models approach. Cambridge University Press, 2002. 